\title{
Ultrasonic speed, density, viscosity and associated acoustical parameters of chloroform solutions of symmetric double Schiff bases at 308.15K
}

\author{
B. J. Gangani, P. H. Parsania* \\ Department of Chemistry, Saurashtra University, Rajkot-360 005, Gujarat, India \\ *E-mail address: phparsania22@gmail.com
}

\begin{abstract}
The density, viscosity and ultrasonic speed $(2 \mathrm{MHz})$ of chloroform and symmetric double Schiff bases have been investigated at $308.15 \mathrm{~K}$. Various acoustical parameters such as specific acoustical impedance $(Z)$, adiabatic compressibility $\left(K_{\mathrm{a}}\right)$, Rao's molarsound function $\left(\mathrm{R}_{\mathrm{m}}\right)$, Vander Waals constant $(b)$, internal pressure $(\pi)$, free volume $\left(V_{f}\right)$, intermolecular free path length $\left(\mathrm{L}_{\mathrm{f}}\right)$, classical absorption coefficient $\left.\left(\alpha / \mathrm{f}^{2}\right)_{\mathrm{Cl}}\right)$ and viscous relaxation time $(\tau)$ were determined using ultrasonic $\operatorname{speed}(U)$, $\operatorname{viscosity}(\eta)$ and density $(\rho)$ data of Schiff bases solutions and correlated with concentration. Increasing linear or nonlinear trends of $\left(\mathrm{Z}, \mathrm{Rm}, \mathrm{b}, \tau\right.$ and $\left.\left(\alpha / \mathrm{f}^{2}\right)_{\mathrm{Cl}}\right)$ and decreasing trend of $\mathrm{K}_{\mathrm{a}}, \mathrm{L}_{\mathrm{f}}, \pi$ and $V_{f}$ with increasing concentration of Schiff bases suggested presence of strong molecular interactions in the solutions and solvophilic nature of the Schiff bases, which is further supported by the positive values of solvation number. The nature and position of substituent also affected the strength of molecular interactions.
\end{abstract}

Keywords: Ultrasonic speed; density; viscosity; acoustical parameters; molecular interactions

\section{INTRODUCTION}

The chemistry of Schiff bases $(-\mathrm{CH}=\mathrm{N}-)$ have played vital role in progress of chemical science $^{1}$. Symmetric double Schiff bases are synthesized by acid catalyzed condensation of aromatic primary diamines with aromatic aldehydes by conventional and microwave irradiation methods ${ }^{2}$. Schiff bases find their applications as catalysis, corrosion inhibitors, analytical reagents, additives in synthetic lubricants and for synthesis of metal complexes due to electron donor properties ${ }^{3-5}$.Schiff bases are also used as a starting material of drug such as antimicrobial, antibacterial, antifungal, antiallergic, antiphlogistic, antitumor, anticancer and antidepressant [6-8]. Drug action is also affected by various kinds of physico-chemical interactions e.g. ionic or covalent, charge-transfer, hydrogen bonding, ionic-dipole interaction, hydrophilic interaction. Density, viscosity and ultrasonic speed data are helpful in analyzing such physico-chemical molecular interactions [9].

In recent years, ultrasonic has become the subject of extensive research in different fields of sciences namely consumer industries, epoxy resin solutions, polymers, engineering, medical field, pharmaceutical industries [10-12]. It is also found most suitable to investigate various organic compounds (liquids) and Schiff bases [13]. Ultrasonic studies in aqueous and non aqueous electrolytic solutions have lead to new insight into ion-solvent interactions and 
provide valuable information about the ionic interactions and the nature and the strength of interactions [14].Recently many investigators have reported the influence of solvent, concentration, temperature and the nature of the substituents on the structure of Schiff bases and molecular interactions in the solutions [15-17].

With a view to understand the molecular interactions occurring in the Schiff base solutions, here with we have reported determination of density, viscosity and ultrasonic speed of the solutions of symmetric double Schiff bases of 1, 1'-bis (4-amino phenyl)cyclohexane in chloroform at $308.15 \mathrm{~K}$ and also various acoustical parameters to support structural modification in the solutions because of molecular interactions.

\section{EXPERIMENTAL}

Chloroform (CF) used in the present study was supplied by Allied Chemical Corporation Vadodara, and purified according to literature method [18]. Schiff bases (SDSB1 to SDSB-5) were synthesized and crystallized according to our previous work [2] (SchemeI). The stock solutions of Schiff bases $(0.10 \mathrm{M})$ were prepared in chloroform at room temperature and from them a series of solutions were prepared and stored in air tight bottles to avoid moisture contact.

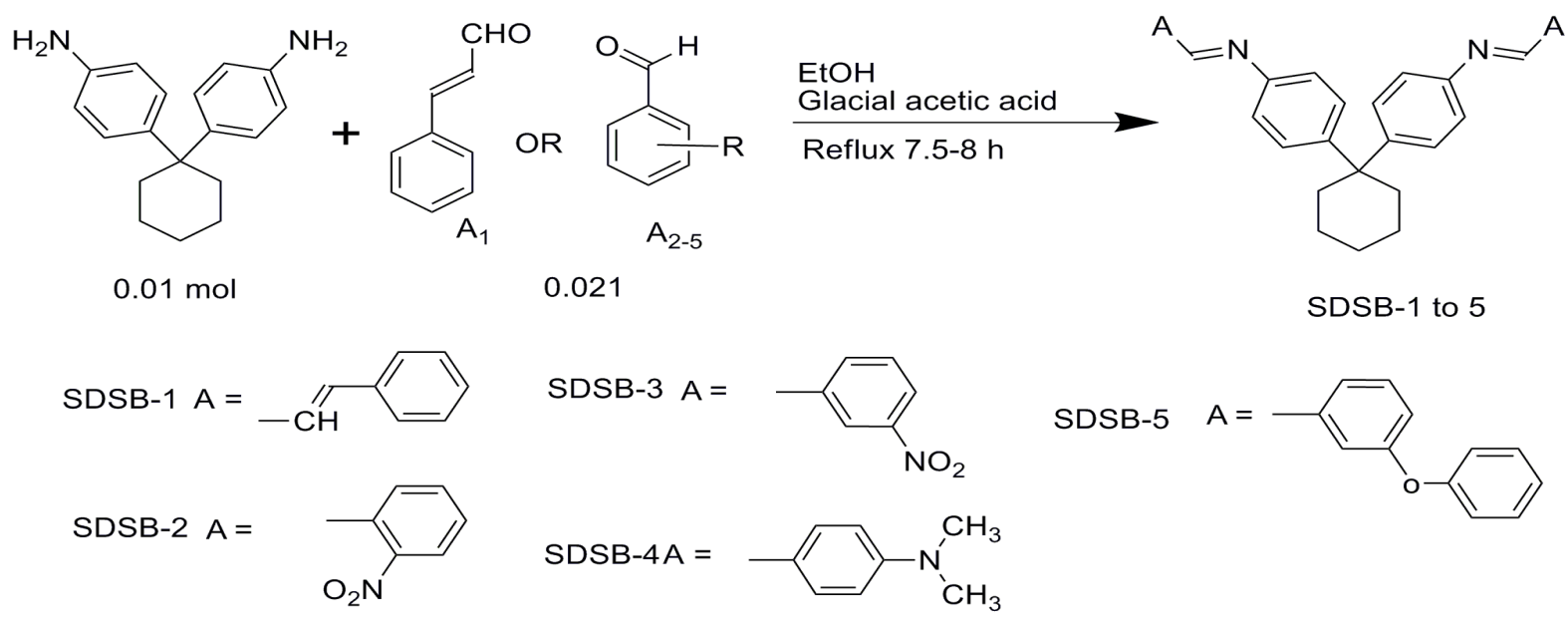

Scheme 1.

\section{MEASUREMENTS}

The density $(\rho)$, viscosity $(\eta)$ and ultrasonic speed (U) measurements of CF and SDSB1 to SDSB-5 solutions were measured at $308.15 \pm 0.1 \mathrm{~K}$ by using specific gravity bottle, Ubbelohde suspended level viscometer and Mittal Enterprise Interferometer (New Delhi) Model No F-81, operating at $2 \mathrm{MHz}$, respectively. The $\rho, \eta$ and $U$ measurements were accurate to $\pm 0.1 \mathrm{~kg} \mathrm{~m}^{-3}, 0.01 \mathrm{mPa} \mathrm{s}$ and $\pm 0.15 \%$, respectively. Using $\rho, \eta$ and $U$ data various acoustical parameters have been derived according to our previous work [19-20]. 


\section{RESULTS AND DISCUSSION}

The $\rho \eta$ and U data of CF, SDSB-1 to SDSB-5 at 308.15K are reported in Table 1. Various acoustical parameters such as specific acoustical impedance(Z), adiabatic compressibility $\left(\mathrm{K}_{\mathrm{a}}\right)$, Rao's molar sound function $\left(\mathrm{R}_{\mathrm{m}}\right)$, Vander Waals constant(b), internal $\operatorname{pressure}(\pi)$, free volume $\left(\mathrm{V}_{\mathrm{f}}\right)$, intermolecular free path length $\left(\mathrm{L}_{\mathrm{f}}\right)$, classical absorption coefficient $\left.\left(\alpha / \mathrm{f}^{2}\right)_{\mathrm{Cl}}\right)$ and viscous relaxation time $(\tau)$ were derived using $\operatorname{density}(\rho)$, viscosity $(\eta)$ and ultrasonic speed(U) data of Schiff bases solutions and are reported in Table 2. These parameters are correlated with concentration (C) of the Schiff bases. The least squares equations along with correlation coefficients $(\gamma)$ are reported in Table 3 from which it is observed that a fairly good to excellent correlation between a given parameter and concentration of Schiff bases was observed. From Table 1, it is observed that the density of SDSB-1 to SDSB-5decreased, while both the viscosity and ultrasonic speed increased with increasing concentration of Schiff bases indicating existence of strong molecular interactions in the solutions [21].In accordance to low of additivity the decrease of density with concentration of Schiff bases also confirmed that the densities of Schiff bases are less than that of chloroform. Molecular interaction affects the cohesive forces and structural modification, which result change in transport, acoustical and thermodynamic properties of the solution under a set of experimental conditions.

Table 1. Variation of density, viscosity, ultrasonic speed with concentration of SDSB-1 to SDSB-5 at $308.15 \mathrm{~K}$.

\begin{tabular}{|c|c|c|c|c|c|c|c|}
\hline \multirow{2}{*}{ Parameter } & \multicolumn{7}{|c|}{ Conc.,moldm ${ }^{-3}$} \\
\hline & $\mathbf{0}$ & 0.01 & 0.02 & 0.04 & 0.06 & 0.08 & 0.1 \\
\hline \multicolumn{8}{|c|}{ SDSB-1 -CF } \\
\hline$\rho, \mathrm{kgm}^{-3}$ & 1460.9 & 1457.3 & 1453.1 & 1449.6 & 1446.4 & 1443.8 & 1441.6 \\
\hline$\eta, \mathrm{mPa} s$ & 0.574 & 0.658 & 0.674 & 0.702 & 0.738 & 0.770 & 0.807 \\
\hline $\mathrm{U}, \mathrm{ms}^{-1}$ & 945.4 & 945.6 & 947.4 & 951.8 & 955.4 & 960.2 & 965.2 \\
\hline \multicolumn{8}{|c|}{ SDSB-2 -CF } \\
\hline$\rho, \mathrm{kgm}^{-3}$ & 1460.9 & 1453.7 & 1448.6 & 1445.8 & 1442.3 & 1439.1 & 1436.2 \\
\hline$\eta, \mathrm{mPa} s$ & 0.574 & 0.639 & 0.671 & 0.720 & 0.763 & 0.811 & 0.866 \\
\hline $\mathrm{U}, \mathbf{m s}^{-1}$ & 945.4 & 950.6 & 954.8 & 964.8 & 967.8 & 973.0 & 976.4 \\
\hline \multicolumn{8}{|c|}{ SDSB-3 -CF } \\
\hline$\rho, \mathrm{kgm}^{-3}$ & 1460.9 & 1452.9 & 1450.0 & 1446.1 & 1442.7 & 1439.5 & 1436.6 \\
\hline$\eta, \mathrm{mPa} s$ & 0.574 & 0.649 & 0.679 & 0.732 & 0.801 & 0.845 & 0.871 \\
\hline $\mathrm{U}, \mathrm{ms}^{-1}$ & 945.4 & 945.6 & 947.4 & 953.6 & 959.4 & 965.4 & 969.6 \\
\hline \multicolumn{8}{|c|}{ SDSB-4 -CF } \\
\hline$\rho, \mathrm{kgm}^{-3}$ & 1460.9 & 1454.2 & 1449.7 & 1445.4 & 1441.6 & 1438.5 & 1436.2 \\
\hline$\eta, \mathbf{m P a} s$ & 0.574 & 0.623 & 0.652 & 0.695 & 0.738 & 0.782 & 0.832 \\
\hline $\mathrm{U}, \mathrm{ms}^{-1}$ & 945.4 & 945.6 & 949.2 & 952.6 & 959.4 & 964.4 & 969.4 \\
\hline \multicolumn{8}{|c|}{ SDSB-5 -CF } \\
\hline$\rho, \mathrm{kgm}^{-3}$ & 1460.9 & 1448.7 & 1444.7 & 1440.8 & 1436.9 & 1433.8 & 1431.4 \\
\hline$\eta, \mathrm{mPa} s$ & 0.574 & 0.590 & 0.634 & 0.725 & 0.756 & 0.778 & 0.796 \\
\hline $\mathrm{U}, \mathbf{m s}^{-1}$ & 945.4 & 949.2 & 951.2 & 954.8 & 957.2 & 961.6 & 965.6 \\
\hline
\end{tabular}


Table 2. Variation of acoustical parameters of SDSB-1 to SDSB-5 with concentration at 308.15K.

\begin{tabular}{|c|c|c|c|c|c|c|c|c|c|}
\hline $\begin{array}{l}\text { Conc., } \\
\text { mol d m }{ }^{-3}\end{array}$ & $\begin{array}{l}\mathrm{Z} \times 10^{-6} \\
\mathrm{kgm}^{-2} \mathrm{~s}^{-1}\end{array}$ & $\underset{\mathbf{K}_{\mathbf{a}} \mathbf{X a}^{-1}}{\mathbf{P a}^{+10}}$ & $\underset{\mathbf{m}^{10 /} \mathbf{s}^{1 / 3} \mathbf{m o l}^{-1}}{\mathbf{R}_{\mathbf{m}} \mathbf{x}}$ & $\underset{\mathbf{m}^{3}}{\mathbf{b} \times 10^{5},}$ & $\underset{\mathrm{m}}{\mathrm{L}_{\mathrm{f}} \times 10^{11}}$ & $\underset{\mathrm{Pa}}{\pi \times 0^{-8}}$ & $\underset{\mathbf{m}^{3}}{\mathbf{V}_{\mathrm{f}} \times \mathbf{1 0}^{7}}$ & $\underset{\mathrm{s}}{\tau \times 10^{13}}$ & $\begin{array}{c}\left(\alpha / f^{2}\right)^{2} c_{1} 11^{14} \\
\mathrm{~s}^{2} \mathrm{~m}^{-1}\end{array}$ \\
\hline & 1.382 & 7.659 & 8.018 & 8.036 & 5.79 & 4.011 & - & 5.862 & - \\
\hline \multicolumn{10}{|c|}{ SDSB-1-CF } \\
\hline 0.01 & 1.393 & 7.674 & 8.124 & 8.142 & 5.8 & 4.233 & 2.581 & 6.729 & 1.403 \\
\hline 0.02 & 1.401 & 7.67 & 8.239 & 8.253 & 5.8 & 4.220 & 2.537 & 6.885 & 1.433 \\
\hline 0.04 & 1.407 & 7.615 & 8.445 & 8.447 & 5.78 & 4.186 & 2.479 & 7.122 & 1.476 \\
\hline 0.06 & 1.411 & 7.574 & 8.65 & 8.642 & 5.76 & 4.178 & 2.384 & 7.49 & 1.537 \\
\hline 0.08 & 1.415 & 7.512 & 8.856 & 8.834 & 5.74 & 4.153 & 2.323 & 7.709 & 1.583 \\
\hline 0.10 & 1.417 & 7.446 & 9.062 & 9.025 & 5.71 & 4.142 & 2.244 & 8.016 & 1.638 \\
\hline \multicolumn{10}{|c|}{ SDSB-2-CF } \\
\hline 0.01 & 1.393 & 7.613 & 8.175 & 8.179 & 5.78 & 4.269 & 2.722 & 6.489 & 1.346 \\
\hline 0.02 & 1.401 & 7.572 & 8.319 & 8.312 & 5.76 & 4.290 & 2.595 & 6.776 & 1.400 \\
\hline 0.04 & 1.407 & 7.493 & 8.602 & 8.537 & 5.73 & 4.280 & 2.500 & 6.987 & 1.476 \\
\hline 0.06 & 1.411 & 7.402 & 8.811 & 8.767 & 5.70 & 4.222 & 2.349 & 7.534 & 1.535 \\
\hline 0.08 & 1.415 & 7.400 & 9.058 & 8.998 & 5.67 & 4.158 & 2.242 & 7.932 & 1.608 \\
\hline 0.10 & 1.417 & 7.303 & 9.300 & 9.228 & 5.66 & 4.097 & 2.113 & 8.434 & 1.703 \\
\hline \multicolumn{10}{|c|}{ SDSB-3-CF } \\
\hline 0.01 & 1.393 & 7.697 & 8.165 & 8.183 & 5.81 & 4.187 & 2.639 & 6.662 & 1.389 \\
\hline 0.02 & 1.401 & 7.683 & 8.289 & 8.303 & 5.80 & 4.211 & 2.521 & 6.955 & 1.448 \\
\hline 0.04 & 1.407 & 7.604 & 8.537 & 8.534 & 5.77 & 4.226 & 2.362 & 7.416 & 1.534 \\
\hline 0.06 & 1.411 & 7.531 & 8.789 & 8.764 & 5.75 & 4.279 & 2.158 & 8.039 & 1.652 \\
\hline 0.08 & 1.415 & 7.451 & 9.033 & 8.984 & 5.72 & 4.256 & 2.083 & 8.392 & 1.714 \\
\hline 0.10 & 1.417 & 7.404 & 9.275 & 9.225 & 5.70 & 4.191 & 2.074 & 8.596 & 1.748 \\
\hline \multicolumn{10}{|c|}{ SDSB-4-CF } \\
\hline 0.01 & 1.393 & 7.691 & 8.156 & 8.174 & 5.81 & 4.106 & 2.805 & 6.390 & 1.333 \\
\hline 0.02 & 1.401 & 7.656 & 8.292 & 8.301 & 5.79 & 4.123 & 2.687 & 6.652 & 1.382 \\
\hline 0.04 & 1.407 & 7.624 & 8.531 & 8.531 & 5.78 & 4.125 & 2.541 & 7.069 & 1.463 \\
\hline 0.06 & 1.411 & 7.536 & 8.780 & 8.761 & 5.75 & 4.112 & 2.434 & 7.416 & 1.524 \\
\hline 0.08 & 1.415 & 7.474 & 9.021 & 8.987 & 5.72 & 4.103 & 2.329 & 7.794 & 1.594 \\
\hline 0.10 & 1.417 & 7.409 & 9.260 & 9.210 & 5.70 & 4.106 & 2.214 & 8.218 & 1.672 \\
\hline \multicolumn{10}{|c|}{ SDSB-5-CF } \\
\hline 0.01 & 1.393 & 7.661 & 8.245 & 8.253 & 5.80 & 3.951 & 3.089 & 6.027 & 1.252 \\
\hline 0.02 & 1.401 & 7.650 & 8.424 & 8.427 & 5.79 & 4.000 & 2.856 & 6.470 & 1.341 \\
\hline 0.04 & 1.407 & 7.613 & 8.759 & 8.753 & 5.78 & 4.091 & 2.476 & 7.363 & 1.521 \\
\hline 0.06 & 1.411 & 7.595 & 9.094 & 9.082 & 5.77 & 4.003 & 2.455 & 7.661 & 1.578 \\
\hline 0.08 & 1.415 & 7.543 & 9.434 & 9.409 & 5.75 & 3.892 & 2.490 & 7.826 & 1.605 \\
\hline 0.10 & 1.417 & 7.493 & 9.771 & 9.733 & 5.73 & 3.780 & 2.540 & 7.954 & 1.624 \\
\hline
\end{tabular}


It is observed that $Z$ ( $\gamma=0.959-0.985)$ increased with increasing concentration of Schiff bases supported molecular interactions in the solution [22]. Both $Z$ and $K_{\mathrm{a}}$ depend upon $\rho$ and $\mathrm{U}$ of the solutions. $\mathrm{K}_{\mathrm{a}}(\gamma=-0.995$ to -0.998$)$ and $\mathrm{L}_{\mathrm{f}}(\gamma=-0.989$ to -0.998$)$ decreased linearly with increasing concentration of Schiff bases confirming aggregation of chloroform molecules around Schiff bases molecules ${ }^{23}$ further supported existence of molecular interactions in the solutions. The intermolecular free path length $\left(\mathrm{L}_{\mathrm{f}}\right)$ is another parameter, which is calculated using ultrasonic speed and adiabatic compressibility. Decrease in intermolecular free path length leads to positive deviation in ultrasonic speed and negative deviation in adiabatic compressibility [24] further supported that the molecules are nearer in the solution [25].

Table 3. The least square equations and correlation coefficients for SDSB-1 to SDSB-5 at $308.15 \mathrm{~K}$.

\begin{tabular}{|c|c|c|c|c|c|}
\hline \multirow{2}{*}{ Parameter } & \multicolumn{5}{|c|}{ Correlation equations (Correlation coefficients, $\gamma$ ) } \\
\hline & SDSB-1-CF & SDSB-2-CF & SDSB-3-CF & SDSB-4-CF & SDSB-5-CF \\
\hline$\rho, \mathrm{kgm}^{-3}$ & $\begin{array}{c}-165.92 \mathrm{C}+1457.2 \\
(-0.982)\end{array}$ & $\begin{array}{c}-180.96 \mathrm{C}+1453.6 \\
(-0.984)\end{array}$ & $\begin{array}{c}-177.75 \mathrm{C}+1453.8 \\
(-0.996)\end{array}$ & $\begin{array}{c}-193.1 \mathrm{C}+1454.2 \\
(-0.983)\end{array}$ & $\begin{array}{c}-187.04 C+1449 \\
(-0.988)\end{array}$ \\
\hline$\eta, \mathrm{mPa} \mathrm{s}$ & $\begin{array}{c}1.5104 \mathrm{C}+0.650 \\
(0.989)\end{array}$ & $\begin{array}{c}2.4479 \mathrm{C}+0.6184 \\
(0.999)\end{array}$ & $\begin{array}{c}2.5715 \mathrm{C}+0.6298 \\
(0.992)\end{array}$ & $\begin{array}{c}2.2696 \mathrm{C} \\
+0.6031 \\
(0.999)\end{array}$ & $\begin{array}{c}2.3419 \mathrm{C}+0.5843 \\
(0.973)\end{array}$ \\
\hline $\mathrm{U}, \mathrm{ms}^{-1}$ & $\begin{array}{c}215.89 \mathrm{C}+943.11 \\
(0.999)\end{array}$ & $\begin{array}{c}291.45 \mathrm{C}+948.84 \\
(0.993)\end{array}$ & $\begin{array}{c}278.03 \mathrm{C}+942.5 \\
(0.998)\end{array}$ & $\begin{array}{c}263.4 \mathrm{C}+943.16 \\
(0.998)\end{array}$ & $\begin{array}{c}177.86 \mathrm{C}+947.71 \\
(0.997)\end{array}$ \\
\hline $\begin{array}{l}\mathrm{Z} \times 10^{-6} \\
\mathrm{~kg} \cdot \mathrm{m}^{-2} \mathrm{~s}^{-1}\end{array}$ & $\begin{array}{c}0.2 \mathrm{C}+1.3982 \\
(0.985)\end{array}$ & $\begin{array}{c}0.2493 \mathrm{C}+1.3945 \\
(0.959)\end{array}$ & $\begin{array}{c}0.2 \mathrm{C}+1.3982 \\
(0.985)\end{array}$ & $\begin{array}{c}0.2493 C+1.394 \\
5(0.959)\end{array}$ & $\begin{array}{c}0.2493 C+1.3945 \\
(0.959)\end{array}$ \\
\hline $\begin{array}{c}\kappa_{\mathrm{a}} \times 10^{+10} \\
\mathrm{~Pa}^{-1}\end{array}$ & $\begin{array}{c}-1.3649 C+7.6933 \\
(-0.998)\end{array}$ & $\begin{array}{c}-3.301 C+7.6344 \\
(-0.983)\end{array}$ & $\begin{array}{c}-3.4499 \mathrm{C}+7.7399 \\
(0.997)\end{array}$ & $\begin{array}{c}-3.1529 \mathrm{C} \\
+7.7279 \\
(-0.995) \\
\end{array}$ & $\begin{array}{c}-1.8255 C+7.6868 \\
(-0.988)\end{array}$ \\
\hline $\begin{array}{c}\mathrm{R}_{\mathrm{m}} \times 10^{4}, \\
\mathrm{~m}^{10 / 3} \mathrm{~s}^{1 / 3} \mathrm{~mol}^{-1}\end{array}$ & $\begin{array}{c}10.4 \mathrm{C}+8.026 \\
(0.999)\end{array}$ & $\begin{array}{c}12.354 \mathrm{C}+8.073 \\
(0.999)\end{array}$ & $\begin{array}{c}12.358 \mathrm{C}+8.0428 \\
(1)\end{array}$ & $\begin{array}{c}12.228 \mathrm{C} \\
+8.0416 \\
(0.999)\end{array}$ & $\begin{array}{c}16.908 \mathrm{C}+8.081 \\
\text { (1) }\end{array}$ \\
\hline $\mathrm{b} \times 10^{5}, \mathrm{~m}^{3}$ & $\begin{array}{c}9.761 \mathrm{C}+8.053 \\
(0.999)\end{array}$ & $\begin{array}{c}11.576 C+8.072 \\
(0.999)\end{array}$ & $\begin{array}{c}11.508 \mathrm{C}+8.0709 \\
(0.999)\end{array}$ & $\begin{array}{c}11.476 \mathrm{C} \\
+8.0677 \\
(0.999) \\
\end{array}$ & $\begin{array}{c}16.414 C+8.0948 \\
\text { (1) }\end{array}$ \\
\hline $\mathrm{L}_{\mathrm{f}} \times 10^{11}, \mathrm{~m}$ & $\begin{array}{c}-1.011 \mathrm{C}+5.8172 \\
(-0.989)\end{array}$ & $\begin{array}{c}-1.3753 \mathrm{C}+5.7877 \\
(-0.990)\end{array}$ & $\begin{array}{c}-1.2466 C+5.8227 \\
(-0.998)\end{array}$ & $\begin{array}{c}-1.2137 \mathrm{C}+5.821 \\
(-0.993)\end{array}$ & $\begin{array}{c}-0.7397 \mathrm{C}+5.8082 \\
(-0.989)\end{array}$ \\
\hline$\pi \times 10^{-8}, \mathrm{~Pa}$ & $\begin{array}{c}-1.0132 \mathrm{C}+4.2377 \\
(-0.984)\end{array}$ & \begin{tabular}{|c|}
$-27.719 C^{2}$ \\
$+0.9251 C$ \\
+4.2736 \\
$(-0.989)$ \\
\end{tabular} & $\begin{array}{c}-36.407 \mathrm{C}^{2} \\
+4.2244 \mathrm{C} \\
+4.1408 \\
(-0.969)\end{array}$ & $\begin{array}{c}-0.28 C+4.1306 \\
(-0.896)\end{array}$ & $\begin{array}{c}-84.334 \mathrm{C}^{2} \\
+7.0524 \mathrm{C} \\
+3.808 \\
(-0.991)\end{array}$ \\
\hline $\mathrm{V}_{\mathrm{f}} \mathrm{x} 10^{7}, \mathrm{~m}^{3}$ & $\begin{array}{c}-3.7244 C+2.617 \\
(-0.998)\end{array}$ & $\mid \begin{array}{c}-6.4984 C+2.7559 \\
(-0.996)\end{array}$ & $\begin{array}{c}70.74 C^{2}-14.257 C \\
+2.7822 \\
(-0.957)\end{array}$ & $\begin{array}{c}-6.300 C+2.8272 \\
(-0.993)\end{array}$ & $\begin{array}{c}186.24 \mathrm{C}^{2} \\
-25.812 \mathrm{C} \\
+3.2986 \\
(-0.977)\end{array}$ \\
\hline$\tau \times 10^{13}, \mathrm{~s}$ & $\begin{array}{c}14.267 \mathrm{C}+6.3881 \\
(0.999)\end{array}$ & $\begin{array}{c}21.157 \mathrm{C}+6.2656 \\
(0.995)\end{array}$ & $\begin{array}{c}22.339 \mathrm{C}+6.5225 \\
(0.989)\end{array}$ & $\begin{array}{c}19.802 \mathrm{C} \\
+6.2334 \\
(0.999) \\
\end{array}$ & $\begin{array}{c}21.986 C+6.003 \\
(0.984)\end{array}$ \\
\hline $\begin{array}{c}\left(\alpha / \mathrm{f}^{2}\right)_{\mathrm{cl} .} 10^{14} \\
\mathrm{~s}^{2} \mathrm{~m}^{-1}\end{array}$ & $\begin{array}{c}2.5929 \mathrm{C}+1.377 \\
(0.999)\end{array}$ & $\begin{array}{c}3.7852 \mathrm{C}+1.3158 \\
(0.997)\end{array}$ & $\begin{array}{c}4.1411 \mathrm{C}+1.3669 \\
(0.986)\end{array}$ & $\begin{array}{c}3.3663 \mathrm{C} \\
+1.3052 \\
(0.999) \\
\end{array}$ & $\begin{array}{c}4.0671 \mathrm{C}+1.2767 \\
(0.921)\end{array}$ \\
\hline
\end{tabular}


The linear increase of $\mathrm{R}_{\mathrm{m}}(\gamma=0.999$ to 1.000$)$ and $\mathrm{b}(\gamma=0.999$ to 1.000$)$ with increasing concentration suggested the absences of complex formation between solute and solvent in the solution. The internal pressure $(\gamma=-0.896$ to -0.991$)$ decrease linearly with increasing concentration of SDSB-1 and SDSB-4, nonlinearly in case of SDSB-2, SDSB-3 and SDSB-5 indicated weakening of cohesive forces [26]

Free volume is the average volume in which the center of molecule can move due to repulsion of the surrounding molecules. It is observed that $\mathrm{V}_{\mathrm{f}}(\gamma=0.957$ to -0.998$)$ decreased linearly with increasing concentration of SDSB-1, SDSB-2 and SDSB-4; and nonlinearly in case of SDSB-3 and SDSB-5.Molecular structure get affected by solvent-solute and solutesolute interactions. The decreasing value of $\mathrm{V}_{\mathrm{f}}$ with increasing concentration of Schiff bases indicated that apparent molar mass of the solute is predominant over apparent molar volume of the solute resulting in decreasing of density of the solution. The decrease in free volume may also be due to close packing of the molecules inside the shield, which may be brought about by strong molecular interactions [27].

Both $\left(\alpha / f^{2}\right)_{\mathrm{cl}}$ and $\tau$ are depend upon $\rho, \eta \mathrm{U}$ and temperature. Both $\left(\alpha / \mathrm{f}^{2}\right)_{\mathrm{cl}}(\gamma=0.921$ to $0.999)$ and $\tau(\gamma=0.964$ to 0.999$)$ increased linearly with concentration of Schiff bases. A contribution of acoustical relaxation is accounted due to entropy fluctuation associated in solution of dynamically formed physical entity. Derived acoustical parameters suggested the solvophilic nature of Schiff bases in chloroform at 308.15K.

The solvation number $\left(\mathrm{S}_{\mathrm{n}}\right)$ is a measure of structure forming or structure breaking tendency of the solute in a solution. The increase in solvation number indicates the structure forming tendency of the solute, whereas decrease in $S_{n}$ indicates structure breaking tendency of the solute ${ }^{28}$. The solvation numbers with increasing concentration of SDSB-1 to SDSB-5 are reported in Table 4. In case of SDSB-1, SDSB-2 and SDSB-4, Sn increased, reached maximum then decreased with increasing concentration. The maximum solvation is observed at $0.06,0.04$ and 0.06 moldm $^{-3}$, respectively for SDSB-1, SDSB-2 and SDSB-4. In case of SDSB-3, Sn decreased with increasing concentration up to $0.04 \mathrm{moldm}^{-3}$ and then increased up to $0.06 \mathrm{moldm}^{-3}$ and then decreased. In case of SDSB-5, Sn decreased considerably up to $0.01 \mathrm{moldm}^{-3}$ and it is increased, reached maximum at about $0.04 \mathrm{moldm}^{-3}$ and then decreased with increasing concentration.

Table 4. Variation of solvation number of SDSB-1 to SDSB-5 solutions 308.15K.

\begin{tabular}{|c|c|c|c|c|c|}
\hline \multirow{2}{*}{$\begin{array}{c}\text { Conc. } \\
\text { moldm }^{-3}\end{array}$} & \multicolumn{5}{|c|}{ Solvation number (Sn) } \\
\cline { 2 - 6 } & SDSB-1 & SDSB-2 & SDSB-3 & SDSB-4 & SDSB-5 \\
\hline 0.01 & 6.9 & 2.7 & -3.2 & 3.8 & -62.6 \\
\hline 0.02 & 8.5 & 2.9 & -10.1 & 9.3 & 42.4 \\
\hline 0.04 & 9.1 & 5.9 & -20.4 & 20.1 & 85.8 \\
\hline 0.06 & 15.2 & 2.0 & 14.3 & 22.1 & 23.8 \\
\hline 0.08 & 10.6 & 4.1 & 8.1 & 8.4 & 23.1 \\
\hline 0.1 & 7.7 & 4.1 & 6.3 & 7.0 & 15.8 \\
\hline
\end{tabular}

The lone pairs of electrons of azomethine, nitro, N,N'-dimethyl, phenoxy groups and chlorine of chloroform are electronegative groups, while hydrogen of azomethine, methyl hydrogen of N,N'- dimethyl and hydrogen of chloroform are electropositive groups. Because of opposite dipole-dipole attraction forces between solvent and solute resulted in structure formation, i.e. H-bonding and of the same type resulted in structure breaking tendency. The 
linear increase with maximum showed that solute-solute interaction is predominant over solvent-solute interaction.

It is likely that SDSB-2 can form both intra and intermolecular H-bonding, while SDSB-1, SDSB-3, SDSB-4 and SDSB-5 can form only intermolecular H-bonding. All the five Schiff bases showed their characteristic solvation tendency due to their different geometric structure containing different substituent, their size and nature.

\section{CONCLUSION}

From the experimental findings it is concluded that symmetric double Schiff bases showed structure forming tendency in chloroform system. Both solvent-solute and solutesolute interactions are observed in the present case. The different structure of the Schiff bases led to diversity into molecular interactions.

\section{Acknowledgments}

The authors are grateful to the Head, Department of Chemistry, Saurashtra University-Rajkot, for laboratory facility.

\section{References}

[1] S. Patai The chemistry of the carbon-nitrogen double bond. John-Wiley and Sons. Ltd. London (1970).

[2] B. J. Gangani, P. H. Parsania, Spectrosc. Lett.40, (2007). 97-112.

[3] D. N. Dhar, C. N. Taploo, J. Sci. Ind. Res.41 (1982) 501-506.

[4] S. H. Abdel-Hafez, Phosphorus, sulfur, and silicon.178(2003)2563-2579.

[5] N.B. Patel, J.C. Patel, Arabian J Chem.4(2011) 403-411.

[6] P. Panneerselvam, B.A. Rather, D.R. Reddy, N.R. Kumar, Euro. J. Med. Chem.44(2009) 2328-2333.

[7] M. Sonmez, M. Celebi, I. Berber, Euro. J. Med. Chem.45(2010) 1935-1940.

[8] M. M. Kamel, H.L .Ali, M. M. Anawar, N. A. Mohamed, A. M. Soliman, Euro. J. Med. Chem. 45 (2010)572-580.

[9] M. Iqbal, R. E.Verrall, Can. J. Chem., 67 (1989) 727-735.

[10] U. G. Pathak, J.V. Patel, P. H. Parsania, J. Solution. Chem.41 (2012)755-765.

[11] S. S. Aswale, S. R. Aswale, R. S. Hajare, Int. J. Pharm. Pharmaceu. Sci.,5(2013) 7679.

[12] B. D. Bhuva, P. H. Parsania, J. Appl. Polym. Sci., 121 (2011) 1304-1310.

[13] M. P. Wadekar, J. Chem. Pharm. Res., 5(2013) 37-41.

[14] S. Kamila, V. Chakravortty, S. Jena, J. Solution. Chem.33 (2004) 365-380.

[15] B. J. Gangani, P. H. Parsania, J. Pure. Appl. Ultrasonic, 30 (2008)90-96. 
[16] S. Baluja, K. P. Vaishnani, Russ. J. Phys. Chem. A, 87 (2013)1322-1327.

[17] S. Baluja, Chinese J. Chemistry, 24(2006)1327-1331.

[18] J. A. Riddick, W. B. Bunger; T. Sakano, Organic Solvents Physical Properties and Methods of Purification, Vol. II, $4^{\text {th }}$ ed., Wiley-Interscience Publication, John Wiley, New York, (1986).

[19] B. J. Gangani, P. H. Parsania, J. Ind. Chem. Soc., 86 (2009),942-949.

[20] B. J. Gangani, P. H. Parsania, J. Chem. Pharm. Res., 6,(2014) 243-247.

[21] K. C. Patil, V. D. Umare, Int. J. Res. Pure \& Appl. Phys.2(2012)25-27.

[22] P. S. There.,Rasayan J. Chem., 6 (2013)111.

[23] R. Premalatha, N. Santhi, Int. Lett. Chem., Phys. and Astro. 14 (2014) 53-64.

[24] A. Tadkalkar, P. Pawar, G. K. Bichile,J. Chem. Phar. Res.3, (2011) 165-168.

[25] S. Geetha, K. Renukadevi, S. Rathika, A. Gomathiyalini, Int. J. Recent Scientific Research,5(2014) 1585-1588.

[26] A. A. Mistry, V. D. Bhandakkar, O. P. Chimankar, Advances in Applied Science Research, 4 (2013) 54-59.

[27] R. Mehra, S. Vats, International Journal of Pharma and Bio Sciences, 1(2010)523529.

[28] N Vekariya: J Movaliya; S Baluja, Iran. J. Chem. Chem. Eng. 27 (2008), 129-135. 